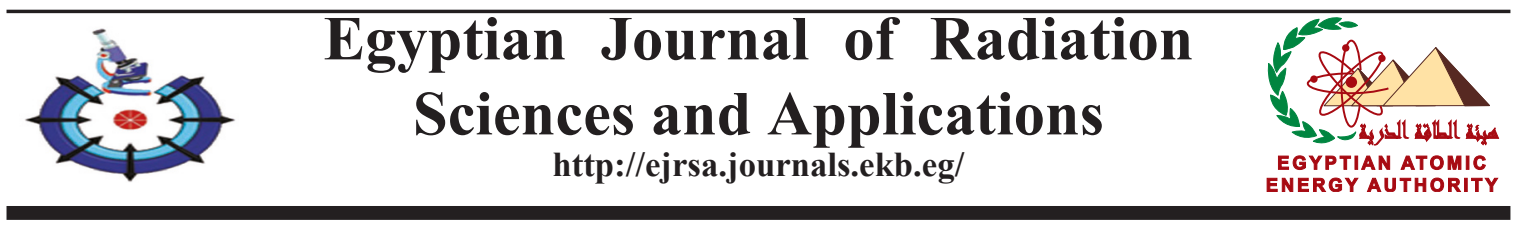

\title{
Comparison of the Efficacy of a Natural Extract Mouthwash with Chlorhexidine on Gingivitis
}

Radwa A. Sallam

Health Radiation Research Department, National Center for Radiation Research and Technology (NCRRT), Atomic Energy Authority (AEA), Cairo, Egypt.

$\mathbf{T}$ HIS STUDY was designed to investigate the effect of pomegranate mouthwash in comparison to $0.2 \%$ chlorohexidine in control of gingivitis. The study was carried out on a total 60 patients. The selected patients were clinically examined and randomly divided into three groups of 20 subjects each. Group A: (control group) included patients with moderate gingivitis, Group B: included patients treated with $0.2 \%$ chlorhexidine mouth rinse with and Group C: included patients treated with Pomegranate Extract mouth rinse. Salivary pH, gingival and plague indices were recorded for three groups. The results of this study reported an increase in the level of salivary $\mathrm{pH}$ in group $\mathrm{B}$ and $\mathrm{C}$ compared to group $\mathrm{A}$ and in group $\mathrm{c}$ compared to group B. A significant decrease in the gingival index in group $\mathrm{C}$ compared to group B was observed. However, there was non-significant difference in plaque index score between both group B and C. According to this study, it could be concluded that Pomegranate Herbal mouthwash could be used effectively in control of gingivitis as an alternative to $0.2 \%$ chlorhexidine with less side effects

Keywords: $0.2 \%$ chlorohexidine mouthwash,Periodontal diseases, Pomegranate mouthwash, Salivary $\mathrm{pH}$.

\section{Introduction}

Gingivitis, is a widely spread inflammatory disease of gingiva with no attachment or alveolar bone loss. Dental plague is one of the etiological factors of gingivitis (Malhotra et al., 2011). 0.2\% chlorhexidine Mouth rinse has proven to be an effective adjunct therapy for plague reduction .However, side effects such as staining of teeth, soft tissue irritation, unpleasant taste, and augmented calculus formation has been recorded (Parwani et al., 2013).

In an urge to limit the side effects, attention of researchers was driven towards the use of natural remedies, which are safe, preventive, and economical for the treatment of periodontal disease.

Pomegranate fruit (Punica granatum), belongs to Punicaceae family. Pomegranate and its derivative exhibits antibacterial, anti-fungal, antioxidant, antiplaque and anti-inflammatory properties, which are good to maintain oral health and in control of gingivitis (Ercisli et al., 2011; Sedigh-Rahimabadi, 2017; Kumar \& Neeraj, 2018)

Diagnosis of periodontal diseases is challenging for both clinical investigators and clinicians (Dietrich et al., 2019). Saliva and crevicular fluid play a main role in initiation and prevention of periodontal disease. Saliva has a $\mathrm{pH}$ normal range of 6.2-7.6. Salivary $\mathrm{pH} 7.0$ usually indicates a healthy dental and periodontal situation (Baliga et al., 2013).

Recent studies recorded significant changes in salivary $\mathrm{pH}$ in relevance to the severity of periodontal disease. Hence, it was concluded that

\#Corresponding author email: radwasallam36@gmail.com

Received 12/3/2020; Accepted 27/4/ 2020

DOI: $10.21608 /$ ejrsa.2020.25770.1095

C2020 National Information and Documentation Center (NIDOC) 
salivary $\mathrm{pH}$ could be used as a quick chairside diagnostic biomarker (Baliga et al., 2013).

The aim of this study is to compare and evaluate and the effect of herbal mouth rinse (pomegranate extract) to $0.2 \%$ chlorhexidine Mouth rinse on the control of gingivitis via the measure of salivary $\mathrm{pH}$ level in addition to, clinical parameters scores.

\section{Subjects and Methods}

This study was carried out in the National Center for Radiation Research and Technology (NCRRT) Nasr City, Cairo, Egypt in a duration of six months. The nature of the study was explained and written informed consents were obtained from all the subjects.

The inclusion criteria inculded subjects with age range 25-45 years with moderate gingivitis and not suffering from any systemic diseases.

Subjects with medical disorders, patients undergoing antibiotic, corticosteroid or other antimicrobial therapy, smokers, in addition to, patients with prosthesis, orthodontic or dental appliances were excluded.

Subjects were randomized into three equal groups:

Preparation of pomegranate extract mouthwash

Pomegranate fruits were purchased from local markets and washed thoroughly with distilled water. The peels were air dried in sunlight and overnight in hot air oven at $60^{\circ} \mathrm{C}$ for 7 days, ground separately into fine powder, and maintained at $-20^{\circ} \mathrm{C}$ in vacuum-sealed packages.

\section{Gamma irradiation}

In tightly capped containers (each $100 \mathrm{~g}$ ), the samples of pomegranate peels were subjected to different doses $5 \mathrm{kGy}$ of gamma radiation using the "Indian Gamma Chamber 4000 A" with a $60 \mathrm{Co}$ source at room temperature. Irradiation was performed in the National Center of Radiation Research and Technology (NCRRT) Nasr City, Cairo, Egypt, at a dose rate $2.492 \mathrm{kGy} / \mathrm{h}$.

\section{Preparation of aqueous extract}

The obtained powder was used to make an aqueous extract in Soxhlet extractor (The powder $20 \mathrm{gm}$ with $100 \mathrm{ml}$ of distilled water). No Sweeteners, flavoring agents, and preservatives were added. The taste of the extract was acceptable.

\section{Collection of unstimulated saliva}

Saliva was collected early in the morning, two hours after the last meal .Patients were asked to rinse thoroughly with distilled water then patients were seated in rest position with their heads tilted forward. Saliva was allowed to flow over a period of 5-min. $5 \mathrm{ml}$ of unstimulated saliva was collected in sterilized graduated containers.

\section{Selection of study sample}

This study was conducted on sixty patients from both sexes aged 25-45 years with moderate gingivitis. The selected patients were clinically examined gingival and plaque indices were measured to estimate baseline record by one examiner. Patients were randomly divided into three groups of 20 subjects each.

Group A: (control group) which included patients with moderate gingivitis with no history of using mouth wash for at least 6 month before the study.

Group B: included patients treated with $0.2 \%$ chlorhexidine mouth rinse with 1:1 dilution in water.

Group C: included patients treated with $3 \mathrm{ml}$ of Pomegranate Extract mouth rinse.

\section{Procedure of salivary $\mathrm{pH}$ estimation}

After collection of saliva, The salivary $\mathrm{pH}$ was determined immediately after collection to avoid any time related $\mathrm{pH}$ changes using $\mathrm{pH}$ meter Jenway 3505 (pH record 1).

Group A were instructed to rinse using $10 \mathrm{ml}$ of chlorhexidine $0.2 \%$ mouthwash with $1: 1$ dilution in water for $2 \mathrm{~min}$. after $10 \mathrm{~min}$ Saliva PH was recorded ( $\mathrm{pH}$ record 2).

Similarly Group B, patients were asked to rinse using $3 \mathrm{ml}$ of pomegranate peel extract for 2 min. Salivary PH was estimated after $10 \mathrm{~min}$ ( $\mathrm{pH}$ record 3).

After recording the saliva $\mathrm{pH}$, patients were given chlorhexidine and pomegranate mouthwashes bottles and asked to use regularly with toothbrushes and paste at least twice a day for 7 days. 
After 7 days of the use of the mouth washes plaque and gingival indices were recorded for each group and compared to baseline value Plaque index by Turskey Gilmore Glickman modification of Quigley Hein plaque index (Turskey et al., 1997), Gingival index by Loe and Silness (Loe \& Silness, 1963).

\section{Statistical analysis}

Data presented as mean and standard deviation (SD). Data explored for normality using Kolmogorov-Smirnov and Shapiro-Wilk tests. Data showed parametric distributions. One Way ANOVA technique was used to compare between tested groups followed by
Touky's post-hoc test.

The significance level was set at $\mathrm{P} \leq 0.05$. Statistical analysis was performed with IBM $\AA$ SPSS ${ }^{\circledR}$ (SPSS Inc., IBM Corporation, NY, USA) Statistics Version 24 for Windows.

\section{Results}

The difference between follow-up periods within the tested parameters are as follows:

A significant change for all tested parameters between time 1 and 2 for control group and test groups at $\mathrm{P} \leq 0.05$ (Table 1, Fig. 1, 2).

TABLE 1. Mean SD for different tested groups

\begin{tabular}{|c|c|c|c|c|c|c|c|}
\hline & \multicolumn{6}{|c|}{ Groups } & \multirow{3}{*}{$P$ value } \\
\hline & \multicolumn{2}{|c|}{$\begin{array}{l}\text { Group A } \\
\text { (control) } \\
\end{array}$} & \multicolumn{2}{|c|}{$\begin{array}{c}\text { Group B } \\
\text { (0.2\% chlorhexidine) }\end{array}$} & \multicolumn{2}{|c|}{$\begin{array}{c}\text { Group C } \\
\text { (pomegranate) }\end{array}$} & \\
\hline & Mean & SD & Mean & SD & Mean & SD & \\
\hline Salivary $\mathrm{pH}$ & 6.845 & 0.074 & $7.26^{\mathrm{b}}$ & 0.070 & $7.43^{\text {a }}$ & 0.049 & $\leq 0.05^{*}$ \\
\hline Gingival Index (GI) & $1.52^{\mathrm{c}}$ & 0.061 & $1.40 \mathrm{~b}$ & 0.059 & 1.26 & 0.058 & $\leq 0.05^{*}$ \\
\hline Plaque Index (PI) & 2.43 & 0.047 & 1.99 a & 0.014 & 1.94 & 0.012 & $\leq 0.05 *$ \\
\hline
\end{tabular}

Means with Same Superscript letter within each row indicates insignificant difference between tested groups.

*= Significance.

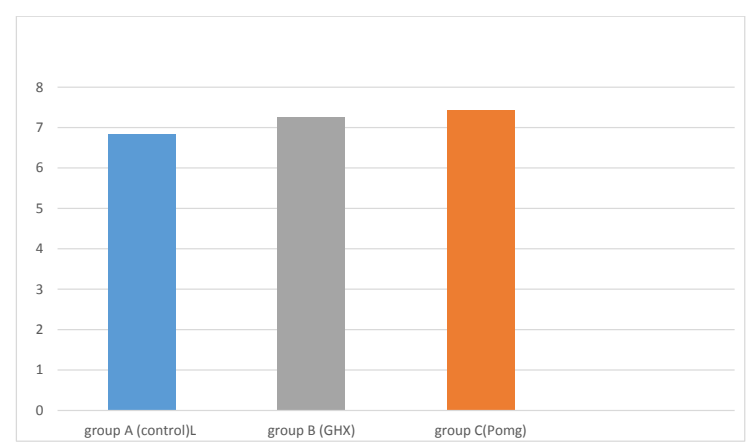

Fig. 1. Histogram showing mean laboratory parameter values for the difference tested group.

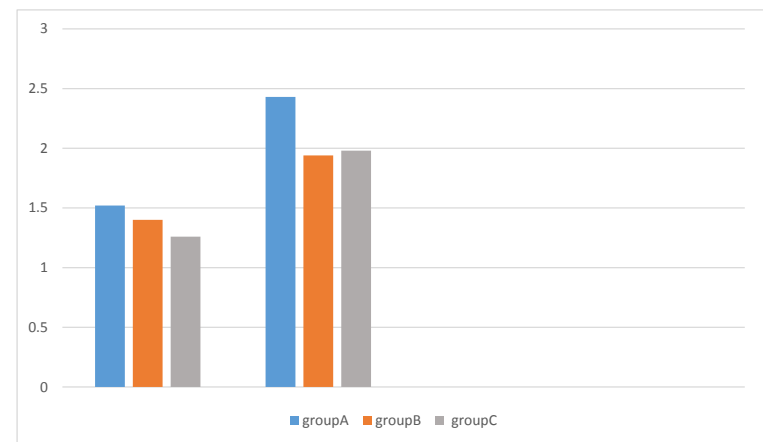

Fig. 2. Histogram showing mean clinical parameter values of gingival and plaque indices, respectively for the difference tested group. 


\section{Discussion}

In the present study, Herbal mouth rinse (pomegranate extract) was investigated as an effective alternative in comparison to chemotherapeutic mouth rinse $(0.2 \%$ chlorhexidine). The choice of pomegranate extract was based on the reported effectiveness of this extract in prevention of gingivitis.

Various studies (Battino et al., 1999; Chidambara et al., 2002; Seeram et al., 2005; Menezes et al., 2006; Lansky \& Newman, 2007; DiSilvestro \& DiSilvestro, 2009; Kiany et al., 2016; Umar et al., 2016; Deepak \& Samuel, 2018; Pedersen et al., 2019) have shown that pomegranate contains agents, especially polyphenolic flavonoids like punicalagins and ellagic acid that result in reduction of oxidative stress in oral cavity, direct anti-oxidant activity, antibacterial activity, and direct removal of plaque from the teeth by discouraging the action of the microorganisms that initiate plaque formation. Moreover, inhibiting prostaglandin and leukotriene formation through inhibition of the eicosanoids enzymes, cyclooxygenase and lipoxygenase, raises the possibility of the use of pomegranate derivatives in anti-inflammatory preparations (Kiany et al., 2016).

Pomgranrtun extract powder was irradiated with gamma radiation at a dose of $5.0 \mathrm{kGy}$. This was due to the effect of gamma irradiation to reduce microbial load, increase the phenolic content and extend the shelf life of the extract without any detrimental effect (Farkas, 2006; Mali et al., 2011; Goodburn \& Wallace, 2013; Ahmad Shah et al., 2014; Zarbakhsh \& Rastegar, 2018; Ashtari et al., 2019). Furthermore, in accordance with Ashtari et al. (2019) and Mali et al. (2011), who deduced that at a dose of t $5.0 \mathrm{kGY}$ gamma irradiation has significantly reduced microbial count of pomegranate peels powder.

In this study, the effects of both mouthwashes (pomegranate vs chlorohexidine) were investigated on salivary $\mathrm{pH}$ as biomarker (Baliga et al., 2013) as well as on clinical parameters (gingival and plague indices). A comparison of the salivary $\mathrm{pH}$ changes after $10 \mathrm{~min}$ rinse showed an increase in the $\mathrm{pH}$ of the saliva sample after pomegranate peels extract mouth rinse as compared to chlorhexidine. This was in agreement with Ahuja et al. (2011), Umar et al. (2016) and Kadam et al. (2019) who concluded that pomegranate herbal mouth rinse when compared with $0.2 \%$ chlorhexidine mouthwash increased the salivary $\mathrm{pH}$ within a short-time interval of mouth rinse. Hence, proving pomegranate mouthwash is favorable in improving gingival status .

Analysis of plaque index values of this study showed that pomegranate mouth rinse recorded less plague index (1.99) compared to chlorhexidine (1.94), but with no significant difference. This was in accordance with, Nóbrega et al. (2015) and Kiany et al. (2016) and in contradiction to Ahuja et al. (2011) who found that chlorhexidine reduced plaque scores to a greater extent as compared with pomegranate mouthwash group. The difference in the results may be because of difference in the methodology and /or the duration of their study.

Analysis of gingival index scores revealed that pomegranate mouthwash was more efficient in reducing gingival score. Similar results were reported by Haffajee et al. (2008), Ahuja et al. (2011) and Sedigh-Rahimabadi et al. (2017).

\section{Conclusion}

Based on the results from the present study, it was proved that Pomegranate Herbal mouthwash was as effective as chlorohexidine in control of gingivitis with less side effects. Hence, it could be considered a more advantageous option compared to the chlorohexidine chemical counterpart.

\section{References}

Ahmad Shah, M., Ahmad Mir, S., Ahmad Pala, S. (2014) Enhancing food safety and stability through irradiation: A Review. Microbial Biotech Food Sci. 3(5), 371-378.

Ahuja, S., Dodwad, V., Kukreja, B.J., Mehra, P., Kukreja. P (2011) A comparative evaluation of efficacy of Punica granatum and chlorhexidine on plaque and gingivitis. J. Int. Clin. Dent. Res. Organ. 3, 29-32.

Ashtari, M., Meysam Ashtari, M., Khademi, O., Soufbaf, M., Afsharmanesh, H., Ali Askari, M., Sarcheshmeh, A. (2019) Effect of gamma irradiation on antioxidants, microbiological properties and shelf life of pomegranate arils. Malas Saveh Scientia Horticulturae, 244, 365-371. 
Baliga, S., Muglikar, S. Kale, R. (2013) Salivary pH: A 7-diagnostic biomarker. J. Indian Soc. Periodontol. 17, 461-5.

Battino, M., Bullon, P., Wilson, M., Newman, H. (1999) Oxidative injury and inflammatory periodontal diseases: The challenge of anti-oxidants to free radicals and reactive oxygen species. Crit. Rev. Oral Biomed. 10, 458-76.

Chidambara Murthy, K.N., Jayaprakasha, G.K., Singh, R.P. (2002) Studies on antioxidant activity of pomegranate (Punica granatum) peel extract using in vivo models. J. Agric. Food Chem. 50, 4791-5.

Deepak, J.C., Samuel, S.R. (2018) Effectiveness of pomegranate mouth rinse in reducing bacterial plaque, gingival inflammation and total salivary proteins over a period of 90 Days: A double-blind randomized trial. J. Int. Acad. Periodontal. 20(3), 110-114.

Dietrich, T., Ower, P., Tank, M. ,West, N.X. ,Walter, C., Needleman, I., Hughes, F.J., Wadia, R., Millard, M.R., Hodge, P.J., Chapple, I.L.C. (2019) Periodontal diagnosis in the context of the 2017 classification system of periodontal diseases and conditions- Implementation in clinical practice. $B r$. Dent. J. 226(1), 16.

DiSilvestro, R.A., DiSilvestro, D.J. (2009) Pomegranate extract mouth-rinsing effects on saliva measures relevant to gingivitis risk. Phytother. Res. 23, 11231127.

Ercisli, S., Gadze, J., Agar, G., Yildirim, N., Hizarci, Y. (2011) Genetic relationships among wild pomegranate (Punica granatum) genotypes from Coruh Valley in Turkey. Genetics and Molecular Research, 10(1), 459-464.

Farkas, J. (2006) Irradiation for better foods. Trends in Food Science \& Technology, 17(4), 148-152.

Goodburn, C., Wallace, C.A.(2013) The microbiological efficacy of decontamination methodologies for fresh produce: A review. Food, 32(2), 418-427.

Haffajee, A.D., Yaskell, T., Socransky, S.S. (2008) Antimicrobial effectiveness of an Herbal mouthrinse compared with an essential oil and a chlorhexidine mouthrinse. J. Am. Dent. Assoc. 139, 606-11.
Kadam, N.S., Kunte, S.S., Patel, A.R., Shah, P.P., Lodaya, R.R., Lakade, L.S. (2019) Comparative evaluation of the effect of pomegranate peel extract and chlorhexidine $0.2 \%$ mouthwash on salivary $\mathrm{pH}$ in children between 6 and 8 years of age: An in vivo study. J. Int. Oral Health, 11, 40-4.

Kiany, F., Niknahad, H., Niknahad, M. (2016) Assessing the effect of pomegranate fruit seed extract mouthwash on dental plaque and gingival inflammation. J. Dent. Res. Rev. 3,117-23.

Kumar, N., Neeraj, K.S. (2018) Functional properties of pomegranate (Punica granatum L.). The Pharma Innovation Journal, 7(10), 71-81.

Lansky, E.P., Newman, R.A. (2007) Punica granatum (pomegranate) and its potential for prevention and treatment of inflammation and cancer. $J$. Ethnopharmacol. 109, 177-206.

Loe, H., Silness, J (1963) Periodontal disease in pregnancy. I. Prevalence and severity. Acta Odontolgica Scand, 21, 533-51.

Mali, A., Khedkar, K., Lele, S. (2011) Effect of gamma irradiation on total phenolic content and in vitro antioxidant activity of pomegranate (Punica granatum L.) Peels. Food and Nutrition Sciences, 2(5), 428-433.

Malhotra, R., Grover, V., Kapoor, A., Saxena, D. (2011) Comparison of the effectiveness of a commercially available herbal mouth rinse with chlorhexidine gluconate at the clinical and patient level. J. Indian Soc. Periodontol. 15, 349-52.

Menezes, S.M., Cordeiro. L,N., Viana, G.S. (2006) Punica granatum (pomegranate) extract is active against dental plaque. J. Herb Pharmacotherapy, 6, 79-92.

Nóbrega, D., Santos, R., Soares, R., Pollianna Muniz Alves, P., Dantas, M., Pereira, J. (2015) Randomized, controlled clinical trial on the clinical and microbiological efficacy of Punica granatum Linn mouthwash. Brazilian Research in Pediatric Dentistry and Integrated Clinic, 15(1), 301.

Parwani, S.R., Parwani, R.N., Chitnis, P.J., Dadlani, H.P., Prasad, S.V (2013) Comparative evaluation of antiplaque efficacy of herbal and $0.2 \%$ chlorhexidine gluconate mouthwash in a 4-day plaque re-growth study. J. Indian Soc. Periodontol. 17(1), 72-77. 
Pedersen, A., Daniel, B., Elstrøm, D. (2019) The role of natural salivary defences in maintaining a healthy oral microbiota. Journal of Dentistry, 80(1), S3S12.

Sedigh-Rahimabadi, M., Fani, M., Rostami-Chijan, M., Zarshenas, M.M., Shams, M. (2017) A traditional mouthwash (Punica granatum var pleniflora) for controlling gingivitis of diabetic patients: A doubleblind randomized controlled clinical trial. J. Evid. Based Complementary Altern Med. 22(1), 59-67.

Seeram, N.P., Adams, L.S., Henning, S.M., Niu, Y., Zhang, Y., Nair, M.G. (2005) In vitro antiproliferative apoptotic and antioxidant activities of punicalagins, ellagic acid and a total pomegranate tannin extract are enhanced in combination with other polyphenols as found in pomegranate juice. $J$.
Nutr. Biochem. 16(6), 360-7.

Turskey, S., Gilmore, N.D., Glickman, I. (1997) Reduced plaque formation by thechloromethyl analogue of vitamin C. J. Periodontal. 41, 41-3.

Umar, D., Dilshad, B., Farhan, M., Ali, A., Baroudi, K. (2016) The effect of pomegranate mouth rinse on Streptococcus mutants count and salivary $\mathrm{pH}$ : An in vivo study. J. Adv. Pharm .Technol. Res. 7, 13-6.

Zarbakhsh, S., Rastegar, S (2018) Influence of postharvest gamma irradiation on the antioxidant system, microbial and shelf life quality of three cultivars of date fruits (Phoenix dactylifera L.). Scientia Horticulturae, 247, 275-286. 